\title{
A specific real-time PCR assay for the detection of Bordetella pertussis
}

Correspondence
Benoit Vincart
bvincart@ulb.ac.be

Received 15 September 2006

Accepted 13 March 2007

\section{Benoit Vincart, ${ }^{1}$ Ricardo De Mendonça, ${ }^{1}$ Sylvianne Rottiers, ${ }^{1}$ Françoise Vermeulen, ${ }^{2}$ Marc J. Struelens ${ }^{1}$ and Olivier Denis ${ }^{1}$}

\author{
${ }^{1}$ Center for Molecular Diagnosis, Department of Microbiology, Erasme Hospital, Université Libre de \\ Bruxelles, Brussels, Belgium \\ ${ }^{2}$ Department of Paediatrics, Erasme Hospital, Université Libre de Bruxelles, Brussels, Belgium
}

\begin{abstract}
A novel real-time PCR (RT-PCR) assay was developed for detection of Bordetella pertussis in respiratory specimens by targeting the pertactin gene. In vitro evaluation with reference strains and quality control samples showed analytical sensitivity equivalent to and specificity superior to those of PCR assays which target the IS481 element. The pertactin-based RT-PCR assay offers better discrimination between B. pertussis and other Bordetella species than previously described assays.
\end{abstract}

\section{INTRODUCTION}

Bordetella pertussis is the aetiological agent of whooping cough or pertussis. In the non-vaccinated population, it primarily affects children less than 6 months of age. The most common manifestations of $B$. pertussis infection are whooping cough and bronchitis with complications including pneumonia, seizures, encephalopathy and possibly sudden infant death (Mattoo \& Cherry, 2005). During the last 15 years, the incidence of pertussis has increased again in different regions of the world despite intensive programmes of infant vaccination (Cordova et al., 2000; De Melker et al., 2000; De Schutter et al., 2003; Gonzalez Moran et al., 2002; Khetsuriani et al., 2001). Adults and adolescents act as a reservoir for infection in very young infants who are not yet fully immunized and who experience severe morbidity. This reservoir exists because vaccination in childhood induces protection for a limited time only (Mattoo \& Cherry, 2005; Von Konig et al., 2002). The emergence and dissemination of $B$. pertussis variant strains that are antigenically different from vaccine strains is another possible cause of this phenomenon (Weber et al., 2001).

In this context, rapid and accurate diagnostic tests for pertussis appear to be needed for improved management of cases and protection of infants. Most of the PCR-based methods described so far for the detection of B. pertussis target the multi-copy insertion sequence IS481 (Chan et al., 2002; Cloud et al., 2003; Poddar, 2003; Reischl et al., 2001), which is also found in other Bordetella species (Muyldermans et al., 2005). Here, we describe a novel PCR assay for specific detection of $B$. pertussis that we have designed by targeting the single-copy pertactin gene, a

Abbreviation: RT-PCR, real-time PCR.
$69 \mathrm{kDa}$ outer-membrane protein which is an important virulence factor of $B$. pertussis. The real-time pertactin PCR (pertactin RT-PCR) can be combined with sequence analysis of $16 \mathrm{~S}$ rRNA genes for the identification of other species of Bordetella.

\section{METHODS}

Bacterial isolates. The assay specificity was evaluated on strains of Bordetella $(n=8)$ and non-Bordetella species $(n=20)$, including: Bordetella pertussis (ATCC 9340 and 9797), Bordetella parapertussis, Bordetella bronchiseptica, Bordetella holmesii, Bordetella hinzii, Bordetella trematum, Bordetella avium, Staphylococcus aureus, Staphylococcus epidermidis, Staphylococcus hominis, Streptococcus pneumoniae, Stenotrophomonas maltophilia, Pseudomonas aeruginosa, Klebsiella pneumoniae, Acinetobacter baumannii, Morganella morganii, Enterobacter aerogenes, Citrobacter freundii, Proteus vulgaris, Burkholderia cepacia (genomovar 1), Escherichia coli, Moraxella catarrhalis, Serratia marcescens, Mycobacterium tuberculosis, Legionella pneumophila and Mycoplasma pneumoniae (type 1 and 2).

All Bordetella strains were cultured on Regan-Lowe charcoal agar containing $10 \%$ defibrinated horse blood and cephalexin $\left(40 \mathrm{ml} \mathrm{l}^{-1}\right)$ (Oxoid). Nucleic acids were extracted from one colony of fresh culture using the QiaAmp DNA mini kit (Qiagen), according to the manufacturer's instructions.

RT-PCR. The primers and probe for the real-time method (Fig. 1) were chosen by alignment of all described pertactin genes and determination of the consensus sequence using the Primer Express software (Applied Biosystems). The fragment to be amplified was checked by BLAST (http://www.ncbi.nlm.nih.gov/BLAST) to avoid false-positive signals due to sequence homology. The TaqMan assays were performed on a GeneAmp 5700 (Applied Biosystems) in a $25 \mu 1$ mix containing $12.5 \mu \mathrm{l}$ TaqMan Universal Master Mix, which included optimized concentrations of AmpliTaq Gold DNA polymerase, AmpErase UNG, dNTPs with UTP, $\mathrm{MgCl}_{2}$ and buffer (Applied Biosystems), $0.375 \mu \mathrm{l}$ of each primer $(300 \mathrm{nM})$ and $0.83 \mu \mathrm{l}$ of the TaqMan probe ( $66 \mathrm{nM})$, purchased from MWG-Biotech AG, 
100

\begin{tabular}{|c|c|}
\hline & \\
\hline prn1 & \\
\hline prn2 & tggcgctgggcgcgetgggcgccgccccggcggcgcatgccgactggaacaaccagtccatcgtc \\
\hline prn3 & tggcgctgggcgcgetgggcgccgccccggcggcgcatgccgactggaacaaccagtccatcgtc \\
\hline prn4 & tggcgctgggcgcgctgggcgccgccccggcggcgcatgccgactggaacaaccagtccatcgtc \\
\hline prn5 & tggcgctgggcgcgetgggcgccgccccggcggcgcatgccgactggaacaaccagtccatcgtc \\
\hline prn6 & tggcgctgggegcgctgggcgccgccceggeggegcatgccgactggaacaaccagtccatcgtc \\
\hline prnt & tggcgctgggcgcgctgggcgccgccccggcggcgcatgccgactggaacaaccagtccatcgtc \\
\hline prns & tggcgctgggcgcgctgggcgccgccccggcggcgcatgccgactggaacaaccagtccatcgtc \\
\hline prng & tggcgctgggcgcgctgggcgccgccccggcggcgcatgccgactggaacaaccagtccatcgtc \\
\hline & tggcgctgggcgcgetgggcgccgccccggcggcgcatgccgactggaacaaccagtccatcgtc \\
\hline & tggcgctgggcgcgetgggcgccgecccggcggcgcatgccgactggaacaaccagtccatcg \\
\hline
\end{tabular}

Consensus TGGCGCTGGGCGCGCTGGGCGCCGCCCCGGCGGCGCATGCCGACTGGAACAACCAGTCCATCGTC

\section{Primer Forward}

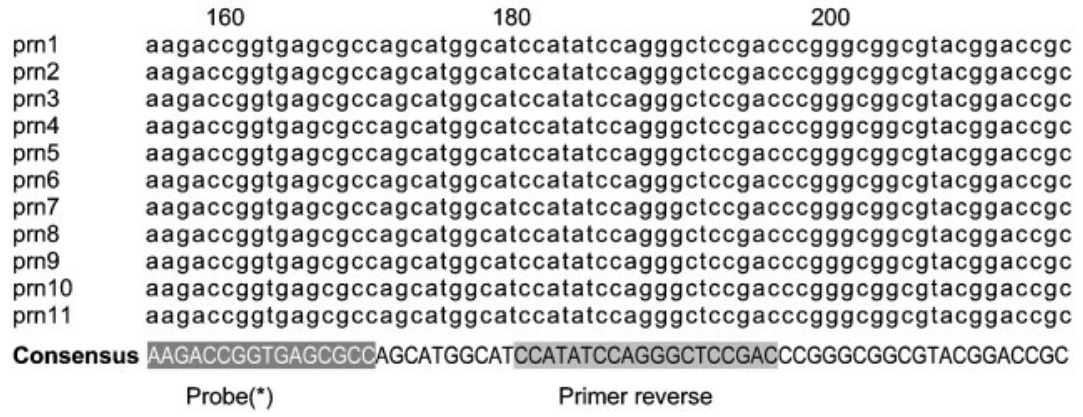

Fig. 1. Alignment of the 11 alleles of the Bordetella pertussis pertactin (prn) gene. $\left(^{*}\right)$ The probe used is modified $5^{\prime}$-FAM-ATCGTCAAGACCGGTGAGCGCC-TAMRA-3' (Taqman probe). Alignment positions were fixed following the complete sequence of the allele 1 pertactin gene. The accession numbers used for the alignment were: AJ011091 (prn1); AJ011092 (prn2); AJ011093 (prn3); AJ011015 (prn4); AJ011016 (prn5); AJ132095 (prn6); AJ133784 (prn7); AJ133245 (prn8); AJ315611 (prn9); AJ784875 (prn10); AJ507642 (prn11). and $5 \mu$ DNA template. An inhibitory control of each sample was performed using the TaqMan Exogenous Internal Positive Control kit (Applied Biosystems).

DNA quantification. Concentrations of $B$. pertussis extracted DNA were measured using the NanoDrop ND-1000 spectrophotometer. Tenfold serial dilutions were prepared in water using extracted DNA from three B. pertussis strains (ATCC 9340 and 9797 and Bord201). DNA dilutions ranging from $6 \log _{10}$ to $0.1 \log _{10}$ copy $\mathrm{ml}^{-1}$ were used to determine the detection threshold of the assay.

DNA sequence analysis. To confirm the identification of Bordetella species, 16S rRNA gene PCR was performed using primers $16 \mathrm{~S}$ rDNA forward [5'-T(A/T)ACACATGCAAGTCGA(A/G)CG-3' (nucleotide positions 22-42)] and 16S rDNA reverse [ $5^{\prime}$-CACCTGTGTTCCGGTTCTCT-3' (nucleotide positions 1019-999)] (numberings deduced from B. pertussis strain Tohama AF366576) chosen using Primer3 software (http://frodo.wi.mit.edu/cgi-bin/primer3/primer3_wwwcgi). A single-round PCR was performed using a PCR mixture $(50 \mu \mathrm{l})$ containing $25 \mu \mathrm{l}$ Master Mix (Promega), $0.2 \mu \mathrm{M}$ each primer and $5 \mu \mathrm{l}$ target DNA. A first step of denaturation at $95^{\circ} \mathrm{C}$ for $10 \mathrm{~min}$ was followed by $40 \mathrm{PCR}$ cycles of $30 \mathrm{~s}$ at $94{ }^{\circ} \mathrm{C}, 1 \mathrm{~min}$ at $58^{\circ} \mathrm{C}$ and $1 \mathrm{~min}$ at $72^{\circ} \mathrm{C}$ and a final extension step for $7 \mathrm{~min}$ at $72^{\circ} \mathrm{C}$. The PCR products ( $998 \mathrm{bp}$ ) were sequenced using the BigDye Terminator kit (Applied Biosystems) according to the manufacturer's instructions. Each fragment obtained was analysed on the $3100 \mathrm{ABI}$ sequencer (Applied Biosystems) and sequences were submitted to BLAST software for identification.

\section{RESULTS AND DISCUSSION}

The pertactin RT-PCR was evaluated with the strains listed in Methods and showed $100 \%$ analytical specificity for $B$. pertussis. Two B. pertussis positive control strains and $10 \mathrm{~B}$. pertussis pertactin variants typed with PFGE in a previous study (De Schutter et al., 2003) were correctly identified by RT-PCR. All Bordetella species were correctly identified with the 16S rRNA gene sequence analysis with high degrees of similarity (over $98 \%$ ).
Standard curves were established with three strains of $B$. pertussis. The linearity of the assay was observed over a range of $6 \log _{10}$ of magnitude. The pertactin RT-PCR assay showed a limit of detection of $1 \log _{10}$ copies of $B$. pertussis DNA $\mathrm{ml}^{-1}$. Inter-assay variability was tested by running the same controls with 10 replicates on different days; intra-assay variability was assessed using the three standard curves in five replicates for the same experiment. Using three $B$. pertussis strains, ATCC 9797, ATCC 9340 and Bord201, the detection rate of the assay was 90,100 and $100 \%$ at $10 \log _{10}$ copies $\mathrm{ml}^{-1}$ of each strain. At $1 \log _{10}$ copies $\mathrm{ml}^{-1}$, the detection rate fell to $50 \%$ for strain ATCC $9797,80 \%$ for strain ATCC 9340 but still achieved $90 \%$ for strain Bord201. The pertactin RT-PCR assay was highly reproducible with a coefficient of variation less than $5 \%$ for inter-assay variability and less than $3 \%$ for intra-assay variability.

We participated in two European external quality assessment ring trials for $B$. pertussis molecular detection (Muyldermans et al., 2005). The first trial checked the sensitivity of protocols and the second one, containing Bordetella non-pertussis, tested the specificity. The analytical sensitivity of the pertactin RT-PCR varied from 9 to 30 c.f.u. $\mathrm{ml}^{-1}$ whereas other laboratories using other PCR methods/ target gene reported results ranging from 3 to 9000 c.f.u. $\mathrm{ml}^{-1}$. The pertactin RT-PCR assay showed $100 \%$ specificity while other participants' results varied in specificity from 73 to $87 \%$, mainly due to misidentification of $B$. holmesii and B. bronchiseptica (Muyldermans et al., 2005).

RT-PCR is increasingly used in laboratory diagnostics. As compared with bacteriological culture, this technique is simple, fast and very sensitive (Dragsted et al., 2004). However, the high sensitivity can lead to false-positive results, depending on the design of the assay. For B. pertussis, 
the main target gene used is the insertion sequence IS481 (Chan et al., 2002; Cloud et al., 2003; Poddar, 2003; Reischl et al., 2001), which is present in 50-100 copies. Insertion sequences are attractive because they occur in multiple copies, which increases the sensitivity of the PCR. However, IS481 is also present in B. holmesii and in B. bronchiseptica (Muyldermans et al., 2005). In recent years, several reports showed pertussis-like infections that were attributed to $B$. holmesii; however, its clinical significance is not yet fully understood (Greig et al., 2001; Mazengia et al., 2000; Reischl et al., 2001; Russell et al., 2001). Insertion sequences of eubacteria are transposable elements that can provide sequence homologies at various sites on DNA molecules and they can result in DNA rearrangements and even in horizontal transfer (Arber, 2000; Mahillon \& Chandler, 1998). Thus protocols using insertion sequences should be controlled by another region of the genome or another method, following previous recommendations (Fry et al., 2004). The novel pertactin PCR assay described here showed an excellent analytical sensitivity for $B$. pertussis DNA detection compared to assays targeting insertion sequences. Furthermore, this novel assay alleviated the problems of cross-reactivity seen for other PCR strategies with other Bordetella species. Therefore, there was no requirement for a confirmation test. Although the pertactin gene exists in 11 known variants (Muyldermans et al., 2004), the region targeted by the pertactin RT-PCR assay described here is conserved in all of them (Fig. 1). In summary, in the clinical laboratory, this novel RT-PCR assay appears promising for rapid diagnosis of pertussis. Awaiting further clinical validation, we recommend the use of the pertactin RTPCR assay as a confirmatory test for specimens showing a positive result with an IS481-based assay.

\section{ACKNOWLEDGEMENTS}

We thank Gaëtan Muyldermans, Department of Microbiology of the Academisch Ziekenhuis, Vrije Universiteit Brussels (VUB), Belgium, for providing Bordetella strains. We also thank Nathalie De Fierlant for the technical assistance with the NanoDrop system.

\section{REFERENCES}

Arber, W. (2000). Genetic variation: molecular mechanisms and impact on microbial evolution. FEMS Microbiol Rev 24, 1-7.

Chan, E. L., Antonishyn, N., McDonald, R., Maksymiw, T., Pieroni, P., Nagle, E. \& Horsman, G. B. (2002). The use of TaqMan PCR assay for detection of Bordetella pertussis infection from clinical specimens. Arch Pathol Lab Med 126, 173-176.

Cloud, J. L., Hymas, W. C., Turlak, A., Croft, A., Reischl, U., Daly, J. A. \& Carroll, K. C. (2003). Description of a multiplex Bordetella pertussis and Bordetella parapertussis LightCycler PCR assay with inhibition control. Diagn Microbiol Infect Dis 46, 189-195.

Cordova, S. P., Gilles, M. T. \& Beers, M. Y. (2000). The outbreak that had to happen: Bordetella pertussis in north-west Western Australia in 1999. Commun Dis Intell 24, 375-379.

De Melker, H. E., Schellekens, J. F., Neppelenbroek, S. E., Mooi, F. R., Rumke, H. C. \& Conyn-van Spaendonck, M. A. (2000). Reemergence of pertussis in the highly vaccinated population of the Netherlands: observations on surveillance data. Emerg Infect Dis 6, 348-357.

De Schutter, I., Malfroot, A., Dab, I., Hoebrekx, N., Muyldermans, G., Pierard, D. \& Lauwers, S. (2003). Molecular typing of Bordetella pertussis isolates recovered from Belgian children and their household members. Clin Infect Dis 36, 1391-1396.

Dragsted, D. M., Dohn, B., Madsen, J. \& Jensen, J. S. (2004). Comparison of culture and PCR for detection of Bordetella pertussis and Bordetella parapertussis under routine laboratory conditions. J Med Microbiol 53, 749-754.

Fry, N. K., Tzivra, O., Li, Y. T., McNiff, A., Doshi, N., Maple, P. A., Crowcroft, N. S., Miller, E., George, R. C. \& Harrison, T. G. (2004). Laboratory diagnosis of pertussis infections: the role of PCR and serology. J Med Microbiol 53, 519-525.

Gonzalez Moran, F., Moreno Civantos, A., Amela Heras, C., Pachon del Amo, I., Garcia del Busto, A., Herrero Carot, C., Herrera Guibert, D. \& Martinez Navarro, F. (2002). A study of whooping cough epidemic outbreak in Castellon, Spain. Rev Esp Salud Publica 76, 311-319.

Greig, J. R., Gunda, S. S. \& Kwan, J. T. C. (2001). Bordetella holmesii bacteraemia in an individual on haemodialysis. Scand J Infect Dis 33, 716-717.

Khetsuriani, N., Bisgard, K., Prevots, D. R., Brennan, M., Wharton, M., Pandya, S., Poppe, A., Flora, K., Dameron, G. \& Quinlisk, P. (2001). Pertussis outbreak in an elementary school with high vaccination coverage. Pediatr Infect Dis J 20, 1108-1112.

Mahillon, J. \& Chandler, M. (1998). Insertion sequences. Microbiol Mol Biol Rev 62, 725-774.

Mattoo, S. \& Cherry, J. D. (2005). Molecular pathogenesis, epidemiology, and clinical manifestations of respiratory infections due to Bordetella pertussis and other Bordetella subspecies. Clin Microbiol Rev 18, 326-382.

Mazengia, E., Silva, E. A., Peppe, J. A., Timperi, R. \& George, H. (2000). Recovery of Bordetella holmesii from patients with pertussislike symptoms: use of pulsed-field gel electrophoresis to characterize circulating strains. J Clin Microbiol 38, 2330-2333.

Muyldermans, G., Pierard, D., Hoebrekx, N., Advani, R., Van Amersfoorth, S., De Schutter, I., Soetens, O., Eeckhout, L., Malfroot, A. \& Lauwers, S. (2004). Simple algorithm for identification of Bordetella pertussis pertactin gene variants. J Clin Microbiol 42, 1614-1619.

Muyldermans, G., Soetens, O., Antoine, M., Bruisten, S., Vincart, B., Doucet-Populaire, F., Fry, N. K., Olcén, P., Scheftel, J. M. \& other authors (2005). External quality assessment for the molecular detection of Bordetella pertussis in European laboratories. J Clin Microbiol 43, 30-35.

Poddar, S. K. (2003). Detection and discrimination of B. pertussis and B. holmesii by real-time PCR targeting IS481 using a beacon probe and probe-target melting analysis. Mol Cell Probes 17, 91-98.

Reischl, U., Lehn, N., Sanden, G. N. \& Loeffelholz, M. J. (2001). Realtime PCR assay targeting IS481 of Bordetella pertussis and molecular basis for detecting Bordetella holmesii. J Clin Microbiol 39, 1963-1966.

Russell, F. M., Davis, J. M., Whipp, M. J., Janssen, P. H., Ward, P. B., Vyas, J. R., Starr, M., Sawyer, S. M. \& Curtis, N. (2001). Severe Bordetella holmesii infection in a previously healthy adolescent confirmed by gene sequence analysis. Clin Infect Dis 33, 129-130.

Von Konig, C. H., Halperin, S., Riffelmann, M. \& Guiso, N. (2002). Pertussis of adults and infants. Lancet Infect Dis 2, 744-750.

Weber, C., Boursaux-Eude, C., Coralie, G., Caro, V. \& Guiso, N. (2001). Polymorphism of Bordetella pertussis isolates circulating for the last 10 years in France, where a single effective whole-cell vaccine has been used for more than 30 years. J Clin Microbiol 39, 4396-4403. 